\title{
Think Piece: Situating Education for Sustainable Development in southern African philosophy and contexts of social-ecological change to enhance curriculum relevance and the common good
}

\author{
Tichaona Pesanayi, Rob O'Donoghue, Rhodes University, South Africa; \\ and Soul Shava, University of South Africa
}

\begin{abstract}
The study opens with a brief review of how education in colonial southern Africa was steered by a succession of externally framed abstractions that have been implemented within the prevailing hegemony of western modernisation that dominated and marginalised indigenous cultures. It probes how, within an expanding functionalist framework, Education for Sustainable Development (ESD) has been similarly constituted as a proposition for implementation. Here the supposition is that implementing ESD as an intervention will transform education into an inclusive and collaborative pedagogy that will shape competences for participants to transform society towards a sustainable future. In an effort to explore the possibility of making a break from a succession of education imperatives functioning as 'salvation narratives' to put things right in Africa, the study explores ESD from a more situated and emergent vantage point within African landscapes, philosophy and cultural practices. This requires a shift from a view of ESD as a perspective to be brought in and enacted to foster change, to ESD as a situated engagement in education as a process where relevance is deliberated and brought out in quality education with high order skills. This perspective exemplifies working with a more fully situated framing of deliberative social learning for the common good. It is explored here to contemplate how socio-cultural processes of deliberative ethics and co-engaged reflexive processes of learning-led change might emerge. Here, also, using a capabilities approach might provide useful starting points for ESD as an expansive process of transformative social learning.
\end{abstract}

\section{An historical vantage point on early education in Africa}

Read in historical relief, it is possible to see that education was commonly initiated from outside and functioned 'behind the desired times to come'. In South Africa, for example, colonial education was part of an inscriptive marginalising of indigenous peoples and their cultures to produce a colonial future. Here an early colonial education focus on literacy played out in times when the production of a literate labour force and consumers was a driver of the expanding imperial juggernaut of modernist globalisation. Into modern times of a slow-down in socioeconomic development and emerging environmental problems, the curriculum reflects a shift to a foregrounding of mathematics, science and technology education for skills development to revitalise the economy and reduce risk in the modern cosmopolitan state. This has shaped a modern, 'risk society' (Beck, 1992) with education imperatives to foster entrepreneurship and also to mediate environmental degradation through inclusive processes of transformative social 
learning (TSL). Here, in simplified overview, the past century of social-ecological change can be seen to have shaped the emergence of early Environmental Education (EE) and an expansive concept of Education for Sustainable Development (ESD) that is currently being merged into a forthcoming focus on Global Citizenship Education (GCEd) for sustainable development (O’Donoghue, 2014).

\section{An accompanying transformation of the commons}

Mukuvisi Woodlands - a small fragment that is a remnant of the earlier Miombo woodlands of Harare today - is now a wildlife park containing eland, a large cattle-like herbivore of the African woodland, amongst other ungulates, and a wide variety of birdlife. These fascinate tourists today as they look over a wetland, now waterhole, and enjoy each other's company in a wildlife park that is within the city limits of Harare. The woodland landscape of rich grassland that reaches out into shaded woods is, however, also the cultural landscape of the Shona, a fire-modified ecosystem of grasses and trees where people thrived with their cattle and where perennial streams watered cattle and homestead food gardens. Today, despite the drought of an El Niño year intensified by emerging climate change in the region, the water is still evident, although the wetland has been partially drained so that it no longer extends into what are now the eastern suburbs of the modern city of Harare. The Shona people in Harare, like indigenous peoples all over the world, are now part of a modern cosmopolitan state within which there is an urgent need for ESD to mediate learning-led change towards a more sustainable future.

The Mukuvisi Woodlands Environmental Education Centre and its woodland ecosystem are an outcome of the colonial game laws and the introduction of preservationist approaches to wildlife conservation. The indigenous people had homesteads that were surrounded by wildlife that were hunted for food, but this began to change as much of the wildlife was decimated by colonial hunters. These changes and the need to conserve dwindling wildlife emerged alongside the need to control the rampant Nagana cattle disease in the hotter lowveld habitats and accompanied the Rinderpest that swept through southern Africa at the turn of the 20th century and into the present, when we have episodic outbreaks of foot and mouth disease. These and other factors contributed to a separation of cattle and wildlife with the colonial creation of wildlife parks that are iconic tourist destinations today.

The colonial processes of intrusive change and the advent of parks produced a curious inversion (O'Donoghue, 1996) for indigenous communities as over a relatively short period, they moved from living in homesteads surrounded by wildlife to many living on the borders of conservation areas from which they were excluded (Brockington, Duffy \& Igoe, 2008). From a lifestyle of being surrounded by wildlife that they hunted together, particularly in the lean, dry winter months, many came to live around parks that they and their cattle were excluded from. These and other slow changes, like the advent of cities, shaped a modern nature/humankind dichotomy both on the now diverse agricultural landscapes and in the intellectual field of ecology that came to be centred on interactions of maintaining natural systems and processes upon which all living things depend. Within this emergent discipline of wildlife ecology that came to inform the modern professional fields of environmental management, the landscape 
was primarily read as natural systems under the threat of change (habitat loss) in modern times of rapid change owing to rampant human expansion and development. This disposition, rooted in modern processes of economic expansion, was starkly evident in the park as a separate wildlife sanctuary for natural habitats where wild things could thrive. This is evident in how many of the parks stand in stark contrast to the human environments around them today and the environmental sciences are underpinned by an ecological idealism founded in colonial fascination with wildlife and wild areas in Africa.

Here ecological and wildlife management research came to constitute a self-validating theory in defence of its founding disposition that parks were developed on natural landscapes that people in Africa had not occupied and impacted (Murombedzi, 2003). For example, numerous studies were undertaken by Ezemvelo KZN Wildlife in collaboration with other management authorities to try to establish the natural baseline for the fire management regimes. This research excluded human-induced fires and their assumed destructive effects and thus came to be centred on lightning strikes. The problem of needing a baseline for the management of grassland and bush encroachment had developed from the 1950s and 1960s as wildlife areas that excluded human influences began to thrive and grasslands for the desirable herds of ungulates that tourists came to see began to recede in areas like the Hluhluwe-Umfolozi Park, for example. It was only into the 1990s that landscape ecologists began to deduce that the expansion of the grasslands and the creation of the African savanna landscape was an outcome of centuries of environmental management by indigenous peoples.

In both the Miombo woodland landscape of the Shona and the Hluhluwe-Umfolozi landscape of the Zulu, the processes used the same medium, fire, but to differing effect. The expansion of the Zululand grasslands developed from the upland into the wooded lowlands, opening up the woodland and creating riverine woodlands. Here the patterns of burning established home ranges for cattle from which wildlife and the Nagana cattle disease were excluded by circular hunting and driving practices. In the case of the Miombo woodlands, it was similarly a cultural landscape produced over millennia of human-nature interactions. Winter and early spring burning with the onset of the rains was centred on the wetland, woodland and riverine areas that were essential for producing the nutritious grasses for summer grazing when the sun was fierce and palatable grasses thrived with the rain and the shade of the trees. Added to this, the Miombo woodlands of southern Africa comprise treed savannah grasslands dominated by indigenous tree legumes of the Brachystegia and Julbernadia genera that produce the necessary nitrogen for grasses to proliferate with the rains. In Zimbabwe, these trees include the musasa (Brachystegia speciformis), mupfuti (Brachystegia boehmii) and munhondo (Julbernadia globiflora). The Shona people have interacted with the Miombo ecosystem and it has been shaped and sustained by and for their livelihoods, which include mixed farming (livestock husbandry and crop cultivation) as well as harvesting of wild resources for food, medicine and for raw materials.

The Shona grazing activities include the timed regular burning of the grasslands - kupisa sango (to burn the woodland or forest) - in the grazing commons (mafuro) - to remove the dry grass biomass at the end of dry winter season, enabling nutritious grasses to emerge at the beginning of the summer rainfall season. The predominantly annual grasses are adapted to this 
fire regime, as are the deciduous tree legumes, which have a thick bark that withstands the regular fires and flush (produce new green leaves) just before the beginning of the summer rainfall. The regular burning is associated with nutrient release.

The naming of the trees is also associated with the Shona people's knowledge of and uses for them. The munhondo is so called because in the dry winter season the dry legume pods crack open due to desiccation, producing a loud clapping noise. Clapping in Shona - a traditional ritual done by the sons-in-law to their in-laws and also by the young to the elders as a sign of respect - is called kurova nhondo, from where the term munhondo is derived (wives also clap to their husbands (and in-laws) as sign of respect, as do people when they meet leaders and also as a means of thanking somebody for receiving something or for a good deed done). The musasa tree is so termed because its branches are usually used to make a shelter, kuvaka musasa, or to fence a field. The inner bark is normally used as bark rope, rwodzi, to tie together the branches making the shelter or poles used in making the sides and roofs of houses. The mupfuti tree is so called because of its ability to easily and quickly develop new shoots from the coppice of a cut down tree. The tree trunks and branches are used for construction and also as firewood. Pfuti is the Shona term for gun. The Shona have a wood harvesting practice in which either the branches are lopped off the trees or the trunk is cut down leaving the tree base (coppicing). Such a wood harvesting practice enables the regeneration of the trees and the recovery of the woodland in the harvested area over time. Similarly, their land preparation practice for cultivation, slash and burn, is done in such a way that when the land loses its natural fertility, it is abandoned to lie fallow (dongo) and regenerate into natural woodland.

The evolution of Miombo woodlands and the other grassland landscapes of southern Africa are closely associated with the cultural practices of the indigenous peoples such as the Shona and Zulu. It is interesting to note here that the association of the Shona people with the Miombo savannah and its development as a socio-ecological (biocultural) landscape is not part of the environmental education processes at the Mukuvisi Woodland Nature Reserve and the Environmental Education Centre in Harare. The same is the case in the Hluhluwe-Umfolozi parks despite the evidence of the hunting pits of King Shaka that are part of the cultural heritage programme for visiting schools and international tourists. Such rich indigenous heritage needs to be incorporated as part of the unfolding discourse on the history of these sites through transformative educational processes that decentre the western hegemony of nature conservation, which tends to prioritise the rights of wildlife over the rights of dispossessed indigenous communities. A re-contextualising discourse in education can pave the way to an inclusive co-existence of plural histories of place that enrich the deliberative learning experiences in these nature reserves.

\section{Framing ESD to restore sustainability to The Commons}

Read in simplifying overview, it is possible to track how the transformation of The Commons (Hardin, 1968) and changing education practices have been 'behind the desired times to come'; in this case, a modern era of risk where there is now a need for ESD to foster transformative change. The educational change is currently playing out in models of processes and social 
imaginaries for producing sustainable futures. Over times of past change, education, not unlike ESD today, has developed as similarly abstracted propositions to be enacted as 'salvation narratives' for producing a desirable future. The colonial past of education reflects an exploitive paternalism, initially to save the native with western forms of literacy and to privatise The Commons so that it became the productive resources of citizens and corporate business in a modern capitalist economy.

In response to emerging risks resulting from the last century of rapid social-ecological change, and not unlike in the recent past when conservation and environmental education were advocated, ESD has now emerged as a model of transformative processes for enabling necessary learning-led change towards a sustainable future. In each case, the envisaged practices for enacting the desired future have not had sufficiently situated models of process for co-engaged participants to mediate desired change. It is becoming apparent that, by approaching education in this way, the educational practices for getting to a desirable end have been surprisingly elusive.

\section{ESD as a concept for implementation to foster transformation}

Over the past decade or so, ESD has emerged as a concept to foster transformative social learning in curriculum settings and expanding education contexts of reflexive social-ecological change. The past United Nations Decade of Education for Sustainable Development has served both to shape and to clarify ESD as a proposition for implementation in five priority areas through a Global Action Programme (UNESCO, 2014) towards transformative learning for future sustainability. Against this broad picture, the question that this paper explores is: how has the modern enactment of education imperatives developed as somewhat blind processes 'behind the desired times to come' when better times have seldom been realised in African contexts of emancipation and empowerment through education? ESD is a compelling proposition for learning-led social-ecological change. It has developed as a response to change as a somewhat arbitrary modernist outcome within escalating socio-economic and political risk. The enactment of ESD as an education process is thus a concern that merits careful review so that it might best be situated and realised through quality education practices that play out in ways that are relevant in emerging African contexts of modernity.

The search for an alternative to an externalised functionalist pedagogical enactment of transformation for enabling students to give effect to social-ecological change is not an easy matter and yet there is evidence of how, working within an African philosophical perspective, students on the margins of modernity have been able to produce and sustain transformations that have enabled them to be successful in modern schooling.

\section{Situated processes of collaborative self-empowerment, literacy and healthy living}

Madzima (2012) describes how, in conditions of poverty and socio-economic collapse in Zimbabwe, a group of young black learners from marginalised communities were successful at school where others failed. She describes how their success was achieved through a sustained collaborative effort, where they drew on cultural resources to transcend the innumerable 
barriers that they faced in daily life and in a schooling system that brought numerous other literacy, learning and assessment task challenges. She writes: 'It was found that they drew strongly on Shona Hunhu cultural resources. These enabled them to become successful despite the daunting conditions in which they found themselves' (Madzima, 2012).

In this way, the learners constituted realities that enabled them to be successful 'through their own local truths and worldviews' that she notes had hitherto been silenced, excluded or remained unrecognised within a dominant "Western Canon" and its education system'. She goes on (Madzima, 2012) to elaborate how:

\begin{abstract}
Consistent with hunhu philosophy, all learners believed they were made in the image of Musikavanhu or Mwari/Great spirit who blesses both the poor and rich as long as they prayed and worked hard to do good and become vanhu chaivo (people of substance) and not marombe (worthless animals). The absence of a strong, moral and coherent subjectivity is conclusively hapana zvemunhu (there is no person there). They respected and listened to the precepts and stories of hunhu wisdom from their parents and community - loving, working together with, sharing, respecting and protecting mhuri (immediate and extended families) and friends. Munhu chaiye aripo anozvibata to attain hunhu (a real person of substance is able to hold him/herself together to attain dignity).
\end{abstract}

She notes how they worked together, forming 'Groupworks' so that they collaborated on learning tasks. Here they described to her how they would not have been successful in passing their exams without working in a way where they 'pooled intellectual and pedagogic resources' to establish a learning community of collaborative purpose and mutual support.

Within the education system of a modern African state, here one finds the social tools and ethical dispositions for the children to create their own successes within a system of education that might enable them to be successful in a changing modern world. Their task is, however, a lot more than this as they must not only be mediated to enter the world of work but the world that they are entering is in need of restorative change.

In another study on relations between home and school where Ubuntu was an important process of solidarity and collaborative endeavour, Maqwelane (2011) found that the inclusion of indigenous knowledge practices through interactions with their grandmothers (Gogos) enhanced literacy and learning in Foundation Phase learners. Her focus was on 'intergenerational healthy living practices' (Maqwelane 2011: ii) that she explored in collaboration with grandmothers on literacy skills in the life skills curriculum. This interactive process served to contextualise the curriculum content in ways that gave the students a relevant foundation for learning to read and write as well as address health issues by exemplifying their heritage knowledge practices.

Both cases reflect situated agency developed through a process of collaborative engagement that draws on indigenous cultural resources to foster success in schooling, suggesting that heritage resources might be important for well constituted models of process like ESD to be brought into useful effect as a foundation for learning to thrive and transcend social-historical processes of marginalisation. 


\section{Towards a situated socio-cultural foundation for ESD}

The Global Action Programme envisaged that modern governments should be supported to situate and enact the abstract concept of ESD as a purposeful activity that produces quality education that is relevant to the times to come. This education must, however, also be relevant to the context and to the peoples that are part of the African landscape of risk in need of change. It is from this vantage point that ESD must be embedded in relation to the social-ecological landscape in ways that activate the cultural capital of the plural cultures within the tapestry of history. In this case there are 16 local languages/dialects across the modern African state of what is Zimbabwe today and a common thread that they all share is hunhu-ubuntu, a philosophy of the socio-ecological landscape and commons of southern Africa. Samkange (1980) notes how the philosophy that is rooted in southern African culture was both situated in the region in diverse dialogical forms and shaped within the socio-political struggle to emerge an African philosophy of Ubuntu. Today hunhu-ubuntu appears to have the necessary situated attributes to provide a necessary philosophical foundation for ESD. Madzima (2012) notes how:

Hunhu is the ethnic, democratic intrinsic-drive success model that helps explain how and with which resources marginalized youth manoeuvre through hostile institutions as they choose to generate cognitive structures and the conditions of their success. Although the storylines of their home and upbringing were interwoven within multiple layers of material impoverishment (i.e. finance, food, clothing, accommodation and education), their identities were unfixed. Through strict discipline and conduct, each embodied learner worked hard to cross, straddle and leap over borders and boundaries whether they were conceptual, structural, cultural, spatial, or temporal.... In turn, these were used in constructing what learners figured were necessary multiple social identities to assist the construction of viable and sustainable academic identities.

Within this research it is possible to note how the philosophy is not only a source of cultural resources to enable collaborative education endeavours but a disposition that resonates with the commons of modernity that are producing risk at a global level.

\section{A situated framing ESD in curriculum practice}

Hunhu-Ubuntu provides a situated capital of commons and community propositions for a deliberative enacting of ESD as a reflexive model of process for expansive learning. It provides the shared cultural capital for framing ESD within emergent socio-cultural processes of meaning-making for narrating learning and change. Deliberative ethics are a necessary capital for reflexive learning as these enable learners to draw on a capital of cultural dispositions and life experiences to raise questions and take up critical vantage points for a dialogical engagement with issues and risk. Here they are also able to situate, contemplate and model The Commons, change-over-time and the common good.

Current ESD training initiatives - such as the ongoing southern African regional teacher training programme in ESD, Sustainability Starts with Teachers (Lotz-Sisitka, Tshiningayamwe 
\& Urenje, 2017), coordinated by UNESCO - need to take into consideration the complex power-knowledge dynamics in situated socio-ecological contexts of practice in southern Africa in an effort to reframe ESD discourses for greater contextual relevance and epistemic resonance. The re-contextualisation of environment and sustainability concerns in ways that articulate with local social-ecological life experiences and indigenous knowledges can foster deepening understanding and resonance amongst educators and learners.

\section{Acknowledgements}

This article is a tribute in loving memory of our colleague, DrVictor Tichaona (Tich) Pesanayi, and his passion for indigenous knowledge research. The paper was conceived in a discussion between Tich and Rob while on a viewing platform overlooking the wetland area at Mukuvisi Woodland Nature Reserve. The ensuing discussion dwelt on socio-ecological insights into nature conservation, drawing from Tich's work with indigenous small-scale farmers in these socio-ecological landscapes and the indigenous knowledge heritage they embody. The discussion evolved into this paper, roping in Soul's interest in indigenous vegetation and its local uses and in the power-knowledge relationships in interactions between indigenous peoples and colonial settlers during and after colonial encounters. We were both enriched by the deepening insights that Tich wove into the narrative as lead author. Our situating deliberations raised many of the concerns explored more fully by the authors who contributed to this Special Edition.

\section{References}

Beck, U. (1992). Risk society: Towards a new modernity. London, Newbury Park, New Dehli: Sage. Brockington, D., Duffy, R. \& Ogoe, J. (2008). Nature unbound: Conservation, capitalism and the future of protected areas. London, Sterling,VA: Earthscan.

Hardin, G. (1968). The tragedy of the commons. Science, 13(3859): 1243-1248.

Lotz-Sisitka, H.B., Tshiningayamwe, S. \& Urenje, S. (2017). Sustainability Starts with Teachers. An ESD professional development programme for secondary teacher educators. Introduction and overview. Harare and Pretoria: UNESCO/SARUA.

Madzima, L. (2012). Low socioeconomic status and identity formation: A case of successful learners in a secondary school in Harare. Unpublished Doctoral Thesis, University of Cape Town, South Africa.

Maqwelane, N. (2011). An exploratory case study of a Foundation Phase learning program to examine how curriculum contextualisation contributes to environmental learning and relevance. Unpublished half-thesis submitted in partial fulfilment of the requirements for the degree of M.Ed (EE), Rhodes University, South Africa.

Murombedzi, J.C. (2003). Pre-colonial and colonial conservation practices in southern Africa and their legacy today. Gland, Switzerland: IUCN.

O’Donoghue, R. (1996). Detached harmonies: A study in/on developing social processes of environmental education in eastern southern Africa. Unpublished Doctoral Thesis, Rhodes University, South Africa. 
O’Donoghue, R.B. (2014). Think Piece: Re-thinking Education for Sustainable Development as transgressive processes of educational engagement with human conduct, emerging matters of concern and the common good. Southern African Journal of Environmental Education, 30, 7-26.

Samkange, S. (1980). Hunhuism or Ubuntuism. Harare:The Graham.

UNESCO (United Nations Educational, Scientific and Cultural Organization). (2014). UNESCO roadmap for implementing the Global Action Programme on Education for Sustainable Development. Paris: UNESCO. 